\title{
MÍDIA E TECNOLOGIA NO CURRÍCULO DE EDUCAÇÃO FíSICA: um estudo exploratório em diálogo internacional ${ }^{1}$
}

\author{
Allyson Carvalho de Araújo \\ Universidade Federal do Rio Grande do Norte - UFRN, Brasil \\ Jeane Felix da Silva \\ Universidade Federal de Alagoas - UFAL, Brasil \\ Alan Patrick Ovens \\ University of Auckland - UOA, Nova Zelândia \\ Jorge Dorfman Knijnik \\ Western Sydney University - WSU, Austrália
}

\begin{abstract}
Resumo
O texto objetiva analisar como a Base Nacional Comum Curricular expressa o crescente interesse pelo tema da mídia e tecnologia no currículo de Educação Física no Brasil, em contraste com outros dois documentos orientadores curriculares de países do hemisfério sul. De caráter exploratória, a pesquisa analisou tais documentos empregando a análise de conteúdo, tendo a mídia-educação como marco teórico/analítico. Os resultados mostram ênfase no pensar criticamente conteúdos de narrativas midiáticas ao passo que houve menor evidência em compreender a linguagem e desenvolvimento da produção de conteúdo midiático. Os achados ressaltam a necessidade de ampliar o olhar do currículo da educação física nos temas explorados por produtos cultura digital.

Palavras-chave: Educação Física; Tecnologia; Mídia; Currículo.
\end{abstract}

\begin{abstract}
The paper aims to analyze how the Common National Curriculum Base expresses the growing interest in the topic of media and technology in the Physical Education curriculum in Brazil, in contrast to two other curriculum guidance documents from countries in the Southern Hemisphere. The research is exploratory and analyzed documents using the analysis content and taking mediaeducation as a theoretical/analytical framework. The results show an emphasis on critically thinking about media narrative contents while there was less evidence of understanding the language and development of media content production. The findings highlight the need to broaden the look of the physical education curriculum on themes explored by digital culture products.
\end{abstract}

Keywords: Physical Education; Technology; Media; Curriculum. 


\section{Introdução}

Em 1995, o filósofo e sociólogo Douglas Kellner chamou a atenção para o efeito que a cultura midiática possui na sociedade. Ao analisar produções dos anos 1990, Kellner demonstrou como essas dramatizam e legitimam pontos de vista, crenças e políticas, além de ter um efeito pedagógico sobre como as pessoas se constituem na contemporaneidade (KELLNER, 2003). Entendemos que esse trabalho segue significativo para compreender a influência da mídia e das tecnologias digitais, sobretudo na forma como jovens consomem e se envolvem com as práticas sociais, dentre elas as práticas corporais. O trabalho de Kellner chama a atenção para duas ideias acerca das transformações culturais que têm implicações no campo da Educação Física (EF). A primeira é a necessidade de entender a produção mediada da cultura de movimento e como seu consumo impacta na percepção e no desenvolvimento da EF escolar. A segunda refere-se à necessidade de uma pedagogia crítica da mídia que ajude os/as jovens a perceberem e participarem da cultura de movimento sem reproduzir irrefletidamente práticas corporais pautadas nas narrativas esportivas midiáticas.

As preocupações acerca da influência das tecnologias digitais e das narrativas midiáticas sobre manifestações culturais abrangem em uma gama de discussões, quando considerados em relação à educação (SHOLLE, 1994; GIROUX, 1994). Existe um debate crescente, em torno do lugar, uso e influência da tecnologia nas escolas, incluindo a discussão da resposta apropriada da educação, mas também a defesa da expansão das políticas de inclusão digital nas escolas (Declaração de Grünwald, 1982; Conferência de Viena, 1999; Proclamação de Alexandria, 2005; Agenda de Paris, 2007; Rede MILID, 2011; Paris Declaração, 2014). Paralelamente, tem-se desenvolvido um conjunto de terminologias para representar o campo de debates das tecnologias de comunicação dentro da educação. É comum percebermos o uso de termos como mídia-educação, educação para a mídia, alfabetização midiática, educomunicação, dentre outros. A despeito das disputas conceituais, observa-se um uso mais comum do termo mídia-educação (ELEÁ, 2015). Contudo, embora tenha se observado uma rápida absorção do debate e, por vezes, do uso de tecnologias digitais e de mídia nas escolas, não foi possível observar o mesmo debate no currículo escolar declarado pelos sistemas de ensino (BUCKINGHAM, 1995).

Pesquisadores/as e professores/as têm buscado formas de integrar tecnologias digitais nas políticas curriculares, assim como nas práticas pedagógicas desenvolvidas nas escolas. Sholle (1994) aponta que, enquanto as produções midiáticas nos provocam a pensar organicamente sobre a nossa sociedade, as propostas para uma pedagogia da mídia se concentraram mais em estabelecer disciplinas isoladas do que em temas relacionados às questões sociais. Esta percepção é evidente em análises de políticas curriculares contemporâneas, em que a mídia e a tecnologia aparecem como uma área de aprendizagem, uma ferramenta pedagógica, um projeto específico ou um tema transversal curricular (FANTIN, 2015; BRUNI, 2010). Em paralelo, observa-se críticas da ausência de comunicação entre as políticas educacionais e o impacto das tecnologias digitais, o que permite inferir que os referenciais curriculares não têm explorado o potencial da relação entre 
educação e mídia de forma crítica porque não os têm pensado de forma orgânica com os demais saberes escolares (MIRANDA, 2015).

$\mathrm{Na}$ área de educação física, existe uma reflexão ainda incipiente sobre como a cultura midiática pode afetar o currículo. Grande parte das pesquisas no campo da EF em relação à tecnologia está centrada na compreensão do uso de tecnologias digitais pelos professores/as (BODSWORTH \& GOODYEAR, 2017; THOMAS \& STRATTON, 2006) ou no engajamento dos/as alunos/as nas aulas (CASEY \& JONES, 2012). Entretanto, estudar a cultura jovem, as produções midiáticas e a onipresença da tecnologia digital se faz fundamental pois estas influenciam a forma como a EF se operacionaliza no currículo escolar.

No Brasil, temos registros sobre os temas de mídia e tecnologia nas duas primeiras versões da Base Nacional Comum Curricular - BNCC (FERREIRA JÚNIOR \& OLIVEIRA, 2016), os quais demonstram um descompasso com as práticas culturais de crianças e jovens na cultura digital, além de uma frágil operacionalização para as intenções didáticas dos/as professores/as.

Diante disso, o objetivo deste artigo é analisar como a BNCC expressa o crescente interesse pelo tema da mídia e tecnologia no currículo de Educação Física, em contraste com outros dois documentos curriculares de países do Hemisfério Sul, especificamente, Nova Zelândia (NZ) e Austrália. Nosso enfoque neste trabalho foi limitado a focalizar três países com os quais estamos familiarizados e que desenvolveram documentos curriculares explícitos para integrar mídia e tecnologia na EF. Este trabalho visa contribuir para a pesquisa contemporânea e internacional, fornecendo uma reflexão de como a tecnologia e a mídia são integradas e moldam a EF escolar.

\section{Mídia, tecnologia e currículo}

O currículo pode ser entendido diacronicamente como o processo contínuo de representar o conhecimento necessário para as futuras gerações em relação às práticas pedagógicas (LUNDGREN, 1991; NEIRA \& SOUZA JÚNIOR, 2016). O currículo, mais do que um texto prescritivo, se constitui na articulação entre os anseios das políticas públicas, das teorias pedagógicas e as práticas escolares.

O currículo diacrônico emerge a partir dos "elementos diferentes que operam em múltiplos níveis do sistema educacional" (OVENS, 2010, p. 27). Assim, o currículo é conjunto de resultados educativos em um estado constante de produção dentro e fora da rede de relações de poder que constituem a natureza da escolarização (OVENS, 2010). O currículo é um campo de contestações em torno daquilo que se deve ensinar e aprender, entre os conhecimentos considerados legítimos de serem abordados nas escolas (SILVA, 2010).

$\mathrm{O}$ impacto das tecnologias digitais no cotidiano de jovens tem requerido atenção dos currículos. As tecnologias digitais estão onipresentes na mediação de tarefas diárias e têm se tornado mecanismos para a produção das culturas contemporâneas. Isto se evidencia nos consumos e produção de sentidos em torno da cultura de movimento ${ }^{2}$, na qual percebe-se 
uma infinidade de aplicativos com vistas a monitorar os níveis de atividade física, registrar dietas, construir comunidades de rotinas de exercícios, aconselhamentos sobre treinos, dicas de como manter-se saudável, meditações guiadas, dentre outros, retroalimentando uma vigilância que opera pela negatividade dos fatores de risco ou pela positividade da gamificação do desempenho (OLIVEIRA \& FRAGA, 2019).

A conectividade proporcionada por tais dispositivos e aplicativos sugere mais do que acesso à informação, produzindo uma cultura na qual discursos particulares sobre movimento, exercício e saúde ganham relevo sob a imperativa ideia de acessibilidade e de positivos resultados ao sujeito. A lógica por trás desses aplicativos, é a de colocar nos indivíduos a responsabilidade pelo autocuidado, reafirmando o argumento de que "não se cuida quem não quer" (FRAGA, 2006). Constituem-se, portanto, em um conjunto de crenças, práticas e conhecimentos, que afetam as formas com que a cultura de movimento é compreendida pela comunidade escolar, o que tem demandado uma reinvenção do currículo da EF com reflexo nas políticas e textos que orientam a vivências das práticas corporais (FRAGA, 2006), inclusive na escola.

A onipresença das tecnologias digitais concorre na formação dos indivíduos/grupos na cultura contemporânea. Estudos têm buscado reconhecer que, aqueles/as nascidos/as dentro da cultura digital, seriam de alguma forma diferentes das gerações anteriores pois teriam um suposto conhecimento universal das tecnologias de informação e comunicação (HARGITTAI, 2010). Assim, uma variedade de nomes tem sido usada para rotular esse grupo, como os nativos digitais (PRENSKY, 2012), iGeneration (FULLAN, 2013) ou geração líquida $(\mathrm{KOH}, 2015)$. Há um esforço em identificar as características que tornam esse grupo distinto, como: a familiaridade com o uso de computadores e smartphones; ter redes sociais ativas e conectadas via internet; e ser tecnologicamente experiente e confiante em ambientes multimídia (HARGITTAI, 2010).

Entendemos tais grupos menos uma geração homogênea de aprendizes e mais como uma descrição de uma possível cultura de aprendizagem possibilitada pela tecnologia (OVENS, GARBETT \& HEAP, 2015). Não se trata de tomar a familiaridade das pessoas nascidas nessa geração com as tecnologias como se fossem naturais, mas constituídas a partir do acesso às tecnologias sendo socializados com e a partir delas.

Contudo, estas categorizações, mesmo vistas com cautela, podem ser úteis ao destacar a natureza diacrônica do currículo. Segundo Prensky (2012), parte da dificuldade do ensino contemporâneo é causada no encontro de expectativas e experiências entre estudantes e professores/as, dentro de um currículo que luta para acompanhar a rápida evolução e o impacto da tecnologia na escolarização. O autor também realça a tensão, ou o que ele chama de bifurcação educacional, da divisão entre o/a nativo/a digital - estudante orientado/a para a aprendizagem como um processo de navegar em contextos emergentes e coletivos - e o/a imigrante digital - professores/as orientados/as para a aprendizagem como um processo de engajamento com resultados previsíveis (PRENSKY, 2012). Nesta bifurcação, tem-se percebido a manutenção do que o autor chama de "currículo do legado", aquele que se ancora mais na tradição dos conteúdos e menos na abertura das vivências contemporâneas. 
Contudo, o hiato entre as formas tradicionais de ensinar e os processos de aprendizagem dos/as estudantes não ocorre apenas quando consideramos o uso de tecnologias digitais. A mediação pedagógica tradicional vem sendo problematizada desde o século passado, vide Manifesto dos Pioneiros da Escola Nova ${ }^{3}$, de 1932, que questionava as formas de educação centradas no conteúdo e nos/as professores/as. Contudo, com a popularização das tecnologias digitais e sua reconhecida potencialidade educativa, intensifica-se o anacronismo dos currículos escolares em relação à vida das pessoas fora dos muros da escola (SIBÍLIA, 2012).

Tal fato destaca a dificuldade em desenvolver um currículo que acomode o impacto das tecnologias digitais. Em pesquisa sobre seis países europeus, Bruni (2010) narra tal dificuldade quando a mídia e a tecnologia se tornaram uma área de aprendizagem independente. A estratégia criou fronteiras disciplinares ao focar na compreensão da tecnologia a despeito da demanda de relacioná-la aos assuntos do universo temático dos/as alunos/as. Em outro ponto problemático, muitas áreas acabaram por empregar a tecnologia apenas como uma ferramenta didática. Entretanto, não se trata de substituir as aulas tradicionais por aulas mediadas por tecnologia se esta vai ser tomada como técnica, mas em investir no uso de tecnologias como agente transformador dos processos educativos. Isso demanda reinventar o modo como temos pensado as escolas, criando outras formas de ser e estar docente. Selwyn (2017) argumenta que há uma necessidade de reconstituir o currículo baseado na "co-criação de conhecimento baseada em tecnologia" (p. 136) na qual a pedagogia e o currículo são redefinidos, tal como experimentado em algumas propostas como "pedagogia de mash-up" (FISHER \& BAIRD, 2009) ou um 'remix learning' (MAHIRI, 2011) que remasterizam práticas pedagógicas já usadas com estratégias que foram possibilitadas com o advento da tecnologia.

No âmbito da EF, muitos/as professores/as ainda não se engajaram no desenvolvimento de uma pedagogia crítica de mídia focada nas transmutações da cultura de movimento. Na literatura contemporânea, encontramos apenas um estudo sobre o currículo brasileiro discutindo a fragilidade entre a tecnologia e o currículo de EF (FERREIRA JÚNIOR \& OLIVEIRA, 2016), e outro focado no currículo neozelandês que enquadra a tecnologia como um elemento emergente que começa a orientar a prática curricular (BOWES \& OVENS, 2014).

Assim, torna-se necessário pesquisar como os documentos oficiais do currículo entendem as relações entre tecnologia e EF como estratégia para explorar como as políticas educacionais se organizam a partir das demandas sociais e das práticas pedagógicas contemporâneas.

\section{Desenho metodológico}

A pesquisa aqui apresentada se caracteriza como exploratória de abordagem qualitativa. Do ponto de vista de seus procedimentos técnicos, trata-se de uma pesquisa documental (GIL, 2008) que se dedica investigar documentos orientadores de currículos. Apesar de apontar 
quantificações de ao longo de sua construção, alerta-se que estas são caminhos para pensar a representatividade dos temas e não para análise em si.

No que se refere à análise dos dados, o estudo trabalha com a análise de conteúdo (BARDIN, 2011), entendida aqui como um conjunto de técnicas de sistematização, trato e análise que busca compreender criticamente o sentido das comunicações no material analisado.

Para realizar uma análise de conteúdo de documentos oficiais de currículo no Brasil, NZ e Austrália utilizamos como desenho metodológico um estudo de múltiplos casos (PATTON, 2002), o que nos permite traçar comparações entre as proximidades e os contrastes entre os diversos currículos aqui analisados.

Os documentos curriculares aqui analisados são: a Base Curricular Comum Nacional BNCC (BRASIL, 2018), The New Zealand Curriculum (MINISTRY OF EDUCATION, 2007) e o Personal Development, Health, and Physical Education K-10 syllabus (NESSA, 2018).

A análise foi desenvolvida em três etapas (BARDIN, 2011). Na primeira etapa, nos familiarizamos com a estrutura e com os conteúdos dos documentos, no que tange aos temas mídia e tecnologia. A partir dessa análise, identificamos quatro unidades textuais que balizaram nossa busca nos documentos e, sobretudo, de seus usos relacionados à EF. Estes índices foram representados pelos termos 'mídia', 'comunicação', 'cultura digital' e 'tecnologia'. Na segunda etapa, recortarmos seus contextos de uso nos documentos e analisamos os sentidos textuais para examinar e decodificar os significados implícitos para sua categorização. Utilizamos as três dimensões da teoria da Mídia-Educação metodológica, a crítica e a produtiva (RIVOLTELLA, 2002; FANTIN, 2006) como pano de fundo teórico que comportou os sentidos dos dados coletados nos documentos e possibilitaram organizar as categorias de análise (RIVOLTELLA, 2002; FANTIN, 2006). Na terceira etapa, refletimos sobre presenças, ausências e inconsistências sobre mídia e tecnologia nesses documentos, contrastando os contextos de sistemas educacionais diversos internacionalmente.

\section{Resultados e discussão}

Inicialmente percebemos que os documentos analisados possuem três características marcantes: a) o reconhecimento da importância das tecnologias digitais; b) a similaridade no uso da nomenclatura e; c) as tecnologias digitais pautando algumas formas de abordagem dos conteúdos de EF nos documentos. Nesses termos, seguimos as reflexões iniciais:

a) A importância crescente das tecnologias digitais é reconhecida nos documentos curriculares a partir de uma narrativa de familiaridade com as tecnologias digitais é essencial para a participação em locais de trabalho e nas sociedades do futuro. Uma evidencia disso é que o documento australiano afirma explicitamente que é baseado em "garantir que o currículo do $\mathrm{PDHPE}^{4}$ seja contemporâneo e focado no futuro" (NESSA, 2018, p.24). O currículo da NZ descreve que um dos principais resultados da escolarização seja "que todos 
os jovens neozelandeses estejam equipados com o conhecimento, as competências e os valores que precisam para serem cidadãos bem-sucedidos no século XXI" (MINISTRY OF EDUCATION, 2007, p. 4). Na BNCC (BRASIL 2018) a necessidade de explorar diferentes tecnologias e recursos digitais também está explícita em várias partes do texto, como algo que atravessa a formação de estudantes da educação básica.

Tais assertivas estabelecem uma agenda ampla que não apenas justifica a relevância da educação para mídia e tecnologia nas escolas, como também descrevem como as necessidades da sociedade estão mudando. Esses documentos situam suas justificativas argumentando que as habilidades e os conhecimento necessárias para o futuro estão mais alinhados às necessidades dos/as estudantes, particularmente no que diz respeito à familiaridade com as tecnologias digitais. Por exemplo:

Em decorrência do avanço e da multiplicação das tecnologias de informação e comunicação e do crescente acesso a elas, os estudantes estão dinamicamente inseridos nessa cultura, não somente como consumidores. Os jovens têm se engajado cada vez mais como protagonistas da cultura digital, envolvendo-se diretamente em novas formas de interação multimidiática e multimodal e de atuação social em rede. (BRASIL, 2018, p. 61)

Os alunos que são usuários competentes de linguagem, símbolos e textos podem interpretar e usar palavras, números, imagens, movimentos, metáforas e tecnologias em diversos contextos. Eles reconhecem como as escolhas de linguagem, símbolo ou texto afetam a compreensão das pessoas e as maneiras pelas quais elas reagem às comunicações. (MINISTRY OF EDUCATION, 2007p. 12)

Esses argumentos são ressonâncias de um debate que tem agenda construída em décadas passadas, como no caso dos experimentos pedagógicos feitos por Buckingham (1995). Contudo, percebe-se uma atualização dos argumentos, ancorada na lógica de novas competências que estão citadas nos documentos analisados.

b) Em segundo lugar, a nomenclatura usada em cada currículo para descrever o campo de tecnologias digitais e da mídia é similar. As diferenças parecem ser atribuíveis à natureza evolutiva do campo: os documentos da NZ (MINISTRY OF EDUCATION, 2007) e da Austrália (NESA, 2018) usam "Tecnologia da informação e comunicação" e a BNCC (BRASIL, 2018) usa "tecnologias digitais de informação e comunicação" para designar a mesma ideia. Essas diferenças são apresentadas no quadro 1. 
Quadro 1: Documentos Curriculares Nacionais, educação física e suas nomenclaturas para o tema de tecnologia e mídia

\begin{tabular}{|c|c|c|c|c|c|}
\hline País & Documento & $\begin{array}{c}\text { Área de } \\
\text { aprendizagem }\end{array}$ & $\begin{array}{c}\text { Ano de } \\
\text { publicação }\end{array}$ & $\begin{array}{c}\text { Área } \\
\text { específica de } \\
\text { aprendizado } \\
\text { de tecnologia }\end{array}$ & $\begin{array}{c}\text { Termo para o } \\
\text { debate sobre } \\
\text { tecnologia }\end{array}$ \\
\hline Brasil & $\begin{array}{l}\text { Base Curricular } \\
\text { Comum Nacional }\end{array}$ & $\begin{array}{l}\text { Educação Física } \\
\text { (Educação Física) }\end{array}$ & 2018 & Não & $\begin{array}{l}\text { Tecnologias digitais } \\
\text { de informação e } \\
\text { comunicação }\end{array}$ \\
\hline $\begin{array}{c}\text { Nova } \\
\text { Zelândia }\end{array}$ & $\begin{array}{l}\text { The New Zealand } \\
\text { Curriculum }\end{array}$ & $\begin{array}{l}\text { Saúde e Educação } \\
\text { Física }\end{array}$ & 2007 & Sim & $\begin{array}{l}\text { Tecnologia da } \\
\text { informação e } \\
\text { comunicação }\end{array}$ \\
\hline Austrália & $\begin{array}{l}\text { Personal Development, } \\
\text { Health, and Physical } \\
\text { Education K- } \\
10 \text { (NSW) }\end{array}$ & $\begin{array}{l}\text { Desenvolvimento } \\
\text { Pessoal, Saúde e } \\
\text { Educação Física }\end{array}$ & 2018 & Não & $\begin{array}{l}\text { Tecnologia da } \\
\text { informação e } \\
\text { comunicação }\end{array}$ \\
\hline
\end{tabular}

Fonte: elaboração própria

Os três documentos discutem mídia e tecnologia usando termos semelhantes. Isso inclui os usos dos termos para entender e avaliar textos de mídia e fontes de informação, bem como para produção e uso de conteúdo de mídia e tecnologia da informação. Esse uso se aproxima da intenção de alfabetização midiática e informacional, conforme proposto pela UNESCO em 2011, para descrever o "tipo de alfabetização esperado na atualidade" (ELEÁ, 2015, p. 13). A UNESCO (2011) enquadra a educação midiática e tecnológica como uma forma de alfabetização porque,

Por um lado, a alfabetização informacional enfatiza a importância do acesso à informação e a avaliação do uso ético dessa informação. Por outro, a alfabetização midiática enfatiza a capacidade de compreender as funções da mídia, de avaliar como essas funções são desempenhadas e de engajar-se racionalmente junto às mídias com vistas à auto expressão. (UNESCO, 2011, p.18)

Embora cada currículo identifique a EF como uma área de aprendizado, apenas os currículos da NZ(MINISTRY OF EDUCATION, 2007) e da Austrália (NESA, 2018) têm a tecnologia como uma área específica de aprendizagem. Na BNCC (BRASIL, 2018) não há área específica para referir a tecnologia, embora esta esteja contemplada em uma das competências gerais da Educação Básica. Torna-se importante destacar que a literatura já registra uma predileção por programas que considerem o tema de mídia e tecnologia como elemento transversal dos currículos. Percebe-se, assim, maior potência interdisciplinar e melhoria de um ensino crítico amplo à revelia dos usos como suportes midiáticos, temas não contextualizados ou eventos esporádicos (BÉVORT \& BELLONI, 2009).

c) Em terceiro lugar, cada documento analisado prescreve objetivos de aprendizagem para currículos de EF emoldurados em torno de tecnologias digitais e de mídia. $\mathrm{Na} \mathrm{NZ}$ 
(MINISTRY OF EDUCATION, 2007) e na Austrália (NESA, 2018) há pelo menos um objetivo de aprendizagem em EF relacionado à mídia e tecnologia por ano de ensino. Em contrapartida, o documento da BNCC (BRASIL, 2018) apresenta menos da metade $(44,44 \%)$ de suas habilidades prescritas para as aprendizagens em EF relacionadas à mídia e tecnologia por ano de ensino (Quadro 2).

Quadro 2: Objetivos de aprendizagens em Educação Física relacionadas à mídia e tecnologia por país

\begin{tabular}{|c|c|c|c|c|}
\hline Country & $\begin{array}{l}\text { Organização } \\
\text { Curricular }\end{array}$ & Ano escolar & $\begin{array}{l}\text { Metas de mídia e } \\
\text { tecnologia }\end{array}$ & $\begin{array}{l}\text { Unidades temáticas / Objetivos de conquista / } \\
\text { Conteúdo }\end{array}$ \\
\hline \multirow{9}{*}{ Brasil } & \multirow{9}{*}{$\begin{array}{l}\text { Ensino } \\
\text { Fundamental }\end{array}$} & 1 ano & & \\
\hline & & 2 ano & & \\
\hline & & 3 anos & & \\
\hline & & 4 anos & & \\
\hline & & 5 anos & & \\
\hline & & 6 ano & $\mathrm{X}$ & Jogos eletrônicos \\
\hline & & 7 ano & $\mathrm{X}$ & Jogos eletrônicos \\
\hline & & 8 anos & $\mathrm{X}$ & Esporte; Ginástica; Luta \\
\hline & & 9 ano & $\mathrm{X}$ & Esporte; Ginástica; Luta \\
\hline \multirow{8}{*}{$\begin{array}{l}\text { Nova } \\
\text { Zelândia }\end{array}$} & \multirow{8}{*}{$\begin{array}{l}\text { Full Primary } \\
\text { school }\end{array}$} & 1 ano & $\mathrm{X}$ & Conceitos e habilidades de movimento \\
\hline & & 2 ano & $\mathrm{X}$ & Conceitos e habilidades de movimento \\
\hline & & 3 anos & $\mathrm{X}$ & Conceitos e habilidades de movimento \\
\hline & & 4 anos & $\mathrm{X}$ & $\begin{array}{l}\text { Saúde Pessoal e Desenvolvimento Físico; } \\
\text { Conceitos de movimento e habilidades } \\
\text { motoras; Relacionamentos com outras } \\
\text { pessoas; Comunidades e ambientes saudáveis }\end{array}$ \\
\hline & & 5 anos & $\mathrm{X}$ & Conceitos e habilidades de movimento \\
\hline & & 6 ano & $\mathrm{X}$ & Conceitos e habilidades de movimento \\
\hline & & 7 ano & $\mathrm{X}$ & Conceitos e habilidades de movimento \\
\hline & & 8 anos & $\mathrm{X}$ & $\begin{array}{l}\text { Conceitos e habilidades de movimento; } \\
\text { Comunidades e ambientes saudáveis. }\end{array}$ \\
\hline \multirow{5}{*}{ Austrália } & \multirow{5}{*}{$\begin{array}{l}\text { Primary } \\
\text { School }\end{array}$} & $\begin{array}{l}\text { Estágio } \\
\text { Inicial } 1 \\
\text { (1 ano) }\end{array}$ & $\mathrm{X}$ & $\begin{array}{l}\text { Saúde, Bem-Estar e Relacionamentos; Estilos de } \\
\text { vida saudáveis, seguros e ativos }\end{array}$ \\
\hline & & $\begin{array}{l}\text { Estágio } 1 \\
(2 \text { anos })\end{array}$ & $\mathrm{X}$ & Estilos de vida saudáveis, seguros e ativos \\
\hline & & $\begin{array}{l}\text { Estágio } 2 \\
(3 \text { anos })\end{array}$ & $\mathrm{X}$ & $\begin{array}{l}\text { Saúde, Bem-Estar e Relacionamentos; Habilidade } \\
\text { de Movimento e Performance; Estilos de vida } \\
\text { saudáveis, seguros e ativos }\end{array}$ \\
\hline & & $\begin{array}{l}\text { Estágio } 3 \\
(4 \text { anos })\end{array}$ & $\mathrm{X}$ & $\begin{array}{l}\text { Saúde, Bem-Estar e Relacionamentos; Estilos de } \\
\text { vida saudáveis, seguros e ativos }\end{array}$ \\
\hline & & $\begin{array}{c}\text { Estágio } 3 \\
(5 \text { anos })\end{array}$ & $\mathrm{X}$ & $\begin{array}{l}\text { Saúde, Bem-Estar e Relacionamentos; Estilos de } \\
\text { vida saudáveis, seguros e ativos }\end{array}$ \\
\hline
\end{tabular}




\begin{tabular}{cccl}
\cline { 2 - 3 } & $\begin{array}{c}\text { Etapa } 5 \\
(6 \text { anos })\end{array}$ & $\mathrm{X}$ & $\begin{array}{l}\text { Saúde, Bem-Estar e Relacionamentos; Estilos de } \\
\text { vida saudáveis, seguros e ativos }\end{array}$ \\
\hline $\begin{array}{c}\text { Secondary } \\
\text { School }\end{array}$ & $\begin{array}{c}\text { Anos } \\
7-10\end{array}$ & $\mathrm{X}$ & $\begin{array}{l}\text { Saúde, Bem-Estar e Relacionamentos; Habilidade } \\
\text { de Movimento e Performance; Estilos de vida } \\
\text { saudáveis, seguros e ativos }\end{array}$ \\
\hline
\end{tabular}

Fonte: dados da pesquisa

Nos três países, os objetivos de aprendizagem não concentram sua atenção em dispositivos tecnológicos e são passíveis de operacionalização com respeito às especificidades escolares. Contudo, sua efetividade em programas de ensino dependeria não apenas da formação docente, mas também das condições de acesso, respeito às construções culturais distintas e apropriações multimodais, com graves discrepâncias entre regiões dos países em tela, em especial no Brasil e na Austrália por seus extensos territórios.

É importante destacar que o documento do currículo oficial australiano (NESA, 2018) possui o maior número de objetivos de aprendizagem relacionados à mídia e tecnologia. No caso da NZ (MINISTRY OF EDUCATION, 2007), embora existam objetivos de aprendizagem relacionados com mídia e tecnologia representados em todos os anos de ensino, a maioria deles está associada de forma tangencial ao tema Ciência e Tecnologia, que tende a enquadrar a tecnologia em termos de usos de equipamento relacionados à atividade física e não em uma perspectiva que possibilite mediar conhecimentos sobre o uso e através dele. Em contrapartida, mesmo o currículo brasileiro (BRASIL, 2018) tendo apresentado o menor número de objetivos de ensino relacionados à mídia e tecnologia, este teve a segunda maior representatividade de elementos textuais comprometidos com a promoção da educação relacionada à mídia e tecnologia em EF como veremos a seguir.

Consideramos que a BNCC (BRASIL, 2018), apensar de ser o mais frágil documento analisado em termos de proposição de objetivos de aprendizagem relacionando a EF com o tema da mídia e tecnologia, este ainda expressa um avanço significativo para o país. Tal constatação se ancora no registro de que na versão preliminar da BNCC "não há conexão entre a EF escolar em seus objetivos de aprendizagem e nos seus ciclos de escolaridade com os termos tecnologia e tampouco com o termo comunicação" (FERREIRA JÚNIOR \& OLIVEIRA, 2016, p. 159). O avanço que pode ser registrado a partir do contraste dos achados nesta pesquisa com o estudo supracitado.

No contínuo das reflexões, analisamos os documentos para entender os usos, os significados e os efeitos da terminologia da mídia e da tecnologia no currículo de EF. As unidades de texto selecionadas para esta pesquisa foram 'mídia', 'comunicação', 'cultura digital' e 'tecnologia'. Primeiramente analisamos as frequências de uso (Quadro 3) que mostram a representatividade dos termos nos documentos. 
Quadro 3: Visão geral da pesquisa de unidades de texto

\begin{tabular}{cccccc}
\hline$\quad$ unidade / Texto & Mídia & Comunicação & Cultura digital & Tecnologia & Total \\
$\begin{array}{c}\text { Documento } \\
\text { Base Curricular Comum Nacional } \\
\text { (Brasil) }\end{array}$ & 11 & 07 & 04 & 08 & 30 \\
\hline $\begin{array}{c}\text { The New Zealand Curriculum (Nova } \\
\text { Zelândia) }\end{array}$ & 02 & 06 & 00 & 13 & 21 \\
\hline $\begin{array}{c}\text { Personal Development, Health, and } \\
\text { Physical Education K-10 Syllabus } \\
\text { (NSW, Austrália) }\end{array}$ & 28 & 31 & 00 & 08 \\
\hline
\end{tabular}

Fonte: dados da pesquisa

O documento brasileiro (BRASIL, 2018) e o australiano (NESA, 2018) têm uma frequência maior de uso de termos-chave do que o documento da NZ (MINISTRY OF EDUCATION, 2007). Essa diferença pode ser explicada em função de suas datas de publicação (Quadro 1) por refletir um crescente foco na tecnologia dentro do currículo ao longo da última década.

Em seguida, analisamos os significados implícitos em sua utilização, combinando-os com os contextos da teoria da mídia-educação (RIVOLTELLA, 2002; FANTIN, 2006). O primeiro contexto é a dimensão metodológica em que a tecnologia é percebida/utilizada de forma instrumental. Por exemplo, na intenção do uso de tecnologias como ferramentas didáticas usadas para facilitar o ensino. Essa dimensão é conhecida como "educar com mídia e tecnologia". O segundo trata da dimensão crítica em que a tecnologia e a mídia se tornam um objeto de estudo em que os/as alunos/as são motivados a entender e posicionar-se criticamente, interpretando o conteúdo de várias formas. Por exemplo, os/as professores/as podem usar filmes para explorar influências da mídia em estereótipos corporais ou escolhas de estilo de vida. Essa dimensão é conhecida como "educar para mídia e tecnologia". O terceiro contexto é conhecido como dimensão produtiva, em que a mídia e a tecnologia são usadas como linguagem para interação social e comunicação. Nesse sentido, o foco é propor que os/as alunos/as produzam conteúdo de mídia e se expressem a partir dele. Essa dimensão é conhecida como 'educar através da mídia e da tecnologia' (FANTIN, 2006).

Usando esses contextos da mídia-educação, analisamos como cada documento expressou suas ênfases em relação às discussões envolvendo EF, mídia e tecnologia no currículo (Quadro 4). 
Quadro 4: Categoria de análise por país

\begin{tabular}{lccccc}
\hline Categoria de análise / & $\begin{array}{c}\text { Conceitos gerais e } \\
\text { relevância sobre } \\
\text { mídia e tecnologia }\end{array}$ & $\begin{array}{c}\text { Educar com } \\
\text { mídia e } \\
\text { tecnologia }\end{array}$ & $\begin{array}{c}\text { Educar para } \\
\text { mídia e } \\
\text { tecnologia }\end{array}$ & $\begin{array}{c}\text { Educar através de } \\
\text { mídia e tecnologia }\end{array}$ & $\begin{array}{c}\text { Total } \\
\text { Baís }\end{array}$ \\
\hline Novil & 14 & 00 & 08 & 08 & 30 \\
\hline Austrália & 12 & 06 & 02 & 01 & 21 \\
\hline Total & 19 & 08 & 33 & 07 & 67 \\
\hline
\end{tabular}

Fonte: dados da pesquisa

Novamente, percebemos que o documento da NZ(MINISTRY OF EDUCATION, 2007) tem uma frequência menor de unidades de texto vinculadas à relação educação e mídia/ tecnologia. Insistimos na sugestão de que isso pode estar relacionado à data de publicação do documento da NZ e à natureza evolutiva do currículo em relação às tecnologias digitais. De fato, os documentos publicados em 2018 têm mais ênfase em educar sobre mídia e tecnologia.

A constatação de que os "conceitos gerais e argumentos para a relevância da mídia e tecnologia" foi a categoria mais representativa na análise dos documentos não foi muito surpreendente, uma vez que os currículos não são revisados na velocidade que as mudanças tecnológicas ocorrem e, portanto, parecem ainda carecer de justificativas para acionar tais elementos em suas propostas. O ritmo lento das mudanças nos documentos de políticas curriculares também reflete a lentidão com que as mudanças ocorrem nas práticas pedagógicas desenvolvidas nas escolas. Nesse sentido, Sibília (2012) indica que a escola contemporânea vive uma crise pois não consegue acompanhar o ritmo de outras mudanças sociais, particularmente aquelas mediadas pelas tecnologias, tornando-se obsoleta em relação aos anseios dos/as estudantes atuais.

Um sintoma desta "lentidão" das escolas e dos documentos que orientam as políticas curriculares é a existência, em alguns documentos, de uma espécie de glossário explicando o que é a área de mídia e tecnologia. Isso demonstra um pressuposto de que professores/as possuem mínima compreensão da área. Esta entrada no glossário australiano ilustra esse ponto:

Ferramentas de TIC - O uso de tecnologias digitais para uma tarefa específica. Envolve também o aprendizado sobre o uso e a prática seguros e éticos dessas ferramentas, por exemplo, processamento de texto, bancos de dados, planilhas, apresentação multimídia, realidade aumentada, tecnologia vestível, colaboração on-line, simulação e comunicação eletrônica. (NESSA, 2018, p. 131).

Em relação ao arcabouço teórico de Mídia-Educação, nossa análise mostra uma clara preferência pela categoria "Educar para mídia e tecnologia". Contudo, segundo a literatura (BUCKINGHAM, 1995; FERREIRA JÚNIOR \& OLIVEIRA, 2016), a maior parte do ensino de mídia e tecnologia ocorre de forma instrumental. Parece que esses documentos 
curriculares contemporâneos abordaram as preocupações levantadas por Buckingham (1995) há mais de vinte anos, no sentido de que processo educativo deva estar mais conectado com a educação para (e não com) mídia e tecnologia.

Este achado nos sugere que os ambientes de educação contemporânea adotaram os dispositivos de tecnologia (em uma primeira fase) e a ênfase atual está sendo focada em pensar criticamente sobre o conteúdo midiático e sua influência na cultura de movimento. Encontramos textos em todos os currículos que dão suporte a essa postura crítica da influência das narrativas midiáticas. Por exemplo:

- Valores esportivos; imagem corporal e aparência; doping; midiatização da luta (BRASIL, 2018).

- Estereótipos; influência da mídia no estilo de vida e bem-estar (MINISTRY OF EDUCATION, 2007).

- Narrativas da mídia sobre saúde; representação de identidade cultural; narrativas da mídia associadas ao jogo; expectativa de gênero; dietas da moda ou; uso seguro da tecnologia (NESSA, 2018).

Por fim, existe ainda uma tímida aproximação com a dimensão produtiva da mídiaeducação, também entendida como "Educar através da mídia e da tecnologia". Isto implica em uma proficiência dos/as professores/as nos usos de construções de narrativas multimodais com tecnologias digitais, especialmente quando os/as estudantes estão se tornando cada vez mais prosumidores (GARCÍA-RUIZ \& PÉREZ, 2015), isto é, produtores/as e consumidores/as de conteúdos digitais, simultaneamente. A análise dos indicadores que se enquadram nesta categoria sugere que há uma preocupação com o ambiente digital (particularmente nas mídias sociais) em que os/as alunos/as estão imersos/as. Este aumento da interatividade permite que os/as alunos/as se conectem a diversas fontes de informação que podem melhorar ou dificultar o aprendizado (MAHONEY \& TANG, 2016).

$\mathrm{O}$ fato de que os contextos da mídia-educação estão representados nos documentos dos currículos oficiais ratifica a ideia de que os/as responsáveis pelas políticas curriculares reconhecem como a cultura digital se tornou importante no campo da educação, mesmo que isso se dê de forma desigual em diferentes países.

\section{Conclusões}

Neste estudo, mostramos que os documentos curriculares do Brasil, NZ e Austrália reconhecem a importância da mídia e tecnologia na educação escolarizada, tanto de forma ampla quanto na área de aprendizagem do currículo de EF. Embora expresso de forma diferente no contexto de cada país, esse reconhecimento é demonstrado na narrativa de que a escolarização deve ser focada nas necessidades das futuras gerações participarem de forma competente em uma sociedade pós-industrial da era da informação. Os argumentos para isso estão refletidos na lógica de que os/as jovens contemporâneos não são apenas consumidores/as mas também usuários/as ativos/as na cultura digital, e que tal proficiência e familiaridade são essenciais para as necessidades futuras de trabalho e da própria vida em 
uma sociedade cada vez mais tecnológica/conectada. Essa ênfase é evidente não apenas nas diretrizes dos documentos estudados, mas sobretudo na forma como cada documento prescreve os objetivos de aprendizagem.

Assim, não enxergamos discrepâncias na relevância da temática da mídia e tecnologia para o currículo da EF dentre os documentos aqui analisados. Contudo, é destacável o fato do documento brasileiro não propor um componente curricular específico para tecnologia, como os demais países estudados. Tal indicador não se caracteriza a priori como um elemento negativo, dado os registros da literatura que a separação de uma área de aprendizagem não garante uma melhor integração de tecnologia no currículo escolar (BRUNI, 2010). Contudo, nossos resultados apontam que os documentos de orientação curricular da NZ e da Austrália têm objetivos de aprendizagens relacionando a EF com a mídia e tecnologia em todos os níveis de ensino, diferentemente do Brasil, que só os apresenta em menos da metade (do sexto ao nono ano) dos 9 anos que compõe o Ensino Fundamental.

Quando analisadas em relação às dimensões da teoria da mídia-educação, é interessante notar que, no documento brasileiro, a ênfase na EF é menor no uso e proficiência com tecnologias (educação com mídia e tecnologia) e maior na relação de análise crítica da mídia, interpretando e avaliando o conteúdo de várias formas de mídia (educar para mídia e tecnologia) e na dimensão produtiva (educar através da mídia e tecnologia). No contraste com os documentos curriculares da NZ e da Austrália, acreditamos que o Brasil avança em não enfatizar referencias de indicações de uso instrumental em seu documento, possuindo uma perspectiva mais crítica e orgânica com a linguagem das mídias e tecnologia.

É importante destacar que o documento de orientações curriculares da Austrália mantenha sua centralidade em uma "educar para a mídia". Ao passo que pensamos que tal atitude é interessante, argumentamos em favor de uma "educação através da mídia e da tecnologia", como forma de ofertar aos/as estudantes a possibilidade de construir suas próprias narrativas sobre práticas corporais. Em outras palavras, defendemos que a análise crítica da mídia, proposta pela teoria de mídia-educação, deve ser sucedida pela expressão dos/das estudantes frente à comunidade escolar. Esse tipo de crítica só é possível se o currículo permitir a compreensão da tecnologia como uma linguagem para interação social e comunicação. Somente quando os/as estudantes têm a oportunidade de usar a tecnologia para criar e compartilhar suas próprias narrativas da cultura de movimento, eles/as podem ter resultados coerentes com os objetivos do currículo nessa área de aprendizagem e também com a sociedade contemporânea.

Por sua vez, o documento de orientações curriculares da NZ tem sua maior recorrência na dimensão instrumental dos usos de mídia e tecnologia e ainda com pouca expressão nas dimensões crítica e produtiva.

Os documentos orientadores dos currículos que analisamos estão respondendo a onipresença que a mídia e as tecnologias digitais estão tendo no campo da EF, ofertando uma estrutura possível aos currículos. Cada documento promove estratégias diferentes para se alinhar ao fenômeno crescente de consumo e circulação de tecnologias digitais e narrativas midiáticas. Observamos que o documento australiano é o mais equilibrado dentre os analisados no que se refere a tensionar diferentes dimensões (instrumental, crítica e 
produtiva) da mídia-educação, enquanto que o documento brasileiro é o menos propositivo no que se refere a objetivos de aprendizagem ou habilidades endereçadas aos diferentes anos da formação escolarizada.

Tal diversidade denuncia estruturas políticas e sociais diversas, ao passo que cria horizontes de aprendizagens mútuos entre os países. As propostas de acionamento do tema das mídias e tecnologias nos documentos de políticas educacionais nacionais faz parte de um sistema coevolutivo, ou seja, tal que o currículo se rearranja à medida em que se mantém a par do crescente poder e diversidade de novas tecnologias na cena cultural. $O$ melhor caminho a seguir é apreciar a necessidade de desenvolver a EF como área de aprendizado capaz de fornecer aos alunos/as os meios para tomar decisões críticas sobre suas práticas corporais, especialmente quando essas são tensionadas e mediadas pelas tecnologias digitais.

Por fim, entende-se que as diferentes estruturas de abordagem da temática entre os países também podem ser observadas como momentos diferentes de aprendizagem em cada contexto e que, no movimento constante de mudanças sociais, cada país pode aprender com as experiências/conhecimentos/representações/opções dos outros para aprimorar as suas próprias experiências/conhecimentos/representações/opções.

\section{Notas:}

1. O presente trabalho foi realizado com apoio da Coordenação de Aperfeiçoamento de Pessoal de Nível Superior - Brasil (CAPES) - Código de Financiamento 001.

2. O conceito de cultura de movimento refere-se às relações existentes entre as formas de se movimentar e a geração de sentido atrelada a este movimento, além da própria compreensão de corpo expressa nestas marcações de cultura.

3. Disponível em: http://www.histedbr.fe.unicamp.br/revista/edicoes/22e/doc1_22e.pdf Acesso em: 01/08/2019.

4. Sigla que se refere o componente curricular Personal development, health, and physical education, que em tradução livre pode ser entendido como "Desenvolvimento pessoal, saúde e Educação Física".

5. Afresco, pintado de 1509 a 1510. Stanza della Segnatura (Vaticano).

\section{Referências}

BARDIN, L. Análise de conteúdo. São Paulo: Edições 70, 2011.

BÉVORT, E; BELLONI, M. L. Mídia-educação: conceitos, história e perspectivas. Educ. Soc, v. 30, n. 109, p. 1081-1102, 2009

BODSWORTH, H.; GOODYEAR, V. V. Barriers and facilitators to using digital technologies in the Cooperative Learning model in physical education. Physical Education and Sport Pedagogy, v. 22, n. 6, p. 563-579, 2017.

BOWES, M.; OVENS, A. Curriculum rhythm and HPE practice: making sense of a complex relationship. Teachers and Curriculum, v. 14, n. 1, p. 21-27, 2014.

BRASIL, Ministério da Educação. Base Nacional Comum Curricular - Documento Final. Brasília, DF: MEC, 
2018.

BRUNI I. The Practice of Media Education: Topics, Issues, and Examples. In: PAROLA, A.; RANIERI, M. (Orgs.). Media Education in Action: a research study in six European countries. Firenze: Firenze University Press, 2010. p. 153-166.

BUCKINGHAM, D. Making media: practical production in media education. London: English \& media center, 1995.

CASEY, A.; JONES, B. Using digital technology to enhance student engagement in physical education. AsiaPacific Journal of Health, Sport and Physical Education, v. 2, n. 2, p. 51-66, 2012.

ELEÁ, I. (Org.). Agents and Voices: a panorama of Media Education in Brazil, Portugal, and Spain. Suécia: Nordicom, 2015.

FANTIN, M. Contexts, Perspectives and Challenges for Media Education in Brazil. In: ELEÁ, I. (Org.). Agents and Voices: a panorama of Media Education in Brazil, Portugal, and Spain. Suécia: Nordicom, 2015. p. 5362.

FANTIN, M. Mídia-educação: conceitos, experiências, diálogos Brasil-Itália. Florianópolis: Cidade Futura, 2006.

FERREIRA JÚNIOR, J.; OLIVEIRA, M R. R. Educação física escolar e tecnologias digitais de informação e comunicação na Base Nacional Comum Curricular... Como é que conecta !!? Motrivivência, v. 28, n. 48, p. 150-167, 2016

FISHER, M.; BAIRD, D. Pedagogical mashup: Gen Y, social media and digital learning styles. In: HIN, L. T. W.; SUBRAMANIAM, R. (Orgs.). Handbook of Research on New Media Literacy at the K-12 Level. Hershey, PA: IGI Global, 2009. p. 48-71.

FRAGA, A. B. Exercício da informação: governo dos corpos no mercado da vida ativa. Campinas: Autores Associados, 2006.

FULLAN, M. Stratosphere: Integrating Technology, Pedagogy and Change Knowledge. Toronto: Pearson Canada, 2013.

GARCÍA-RUIZ, R.; PÉREZ, V. G. Media Literacy in Spain: a brief panorama and a good practices proposal. In: ELEÁ, I. (Org.). Agents and Voices: a panorama of Media Education in Brazil, Portugal, and Spain. Suécia: Nordicom, 2015. p. 251-256.

GIL, A. C. Como elaborar projetos de pesquisa. São Paulo: Atlas, 2008.

GIROUX, H. Disturbing Pleasures. New York: Routledge, 1994.

HARGITTAI, E. Digital Na(t)ives?: Variação nas habilidades e usos da Internet entre os membros da "Geração Net”. Sociological Inquiry, v. 80, n. 1, p. 92-113, 2010.

KELLNER, D. Cultura de Mídia: Estudos culturais, identidade e política entre o moderno e o pós-moderno. Londres: Routledge, 2003.

$\mathrm{KOH}, \mathrm{C}$. Motivation, leadership and curriculum design: Engaging the Net Generation and 21st Century learners. Cingapura: Springer, 2015.

LUNDGREN, U. P. Between education and schooling. Outlines of a diachronic curriculum theory. Geelong: Deakin University Press, 1991.

MAHIRI, J. Digital tools in urban schools: mediating a remix of learning. Ann Arbor: University of Michigan Press, 2011.

MAHONEY, L. M.; TANG, T. Strategic social media: From marketing to social change. Hoboken, NJ: WileyBlackwell, 2016.

MINISTRY OF EDUCATION. The New Zealand Curriculum. Wellington: Learning Media Limited, 2007.

MIRANDA, L. T. Media, Reflection, and Action: An Overview of Media-Education Activities in Formal and Informal Contexts of Brazilian Education. In: ELEÁ, I. (Org.). Agents and Voices: a panorama of Media 
Education in Brazil, Portugal, and Spain. Suécia: Nordicom, 2015. p. 75-82.

NEIRA, M. G.; SOUZA JÚNIOR, M. A Educação Física na BNCC: procedimentos, concepções e efeitos. Motrivivência, v. 28, n. 48, p. 188-206, 2016.

NESA, NSW Education Standards Authority. Personal Development, Health and Physical Education K-10 Syllabus. Sydney: NSW Education Standards Authority, 2018.

OLIVEIRA, B. N.; FRAGA, A. B. O professor-código: aplicativos fitness e a "virada" nos mecanismos de vigilância [Internet]. In: Anais do XXI Congresso Brasileiro das Ciências do Esporte e VIII Congresso Internacional das Ciências do Esporte; 2019; Natal, Brasil. Natal: Colégio Brasileiro de Ciências do Esporte, 2019, p. 1-6. Disponível em: http://congressos.cbce.org.br/index.php/conbrace2019/8conice

OVENS, A.; GARBETT, D.; HEAP, R. Using assessment to enhance learning for the Net Generation. In: KOH, C. (Org.). Motivation, leadership and curriculum design: Engaging the Net Generation and 21st Century learners. Cingapura: Springer, 2015. p. 173-184.

OVENS, A. The New Zealand Curriculum: emergent insights and complex renderings. Asia-Pacific Journal of Health, Sport and Physical Education, v. 1, n. 1, p. 27-32, 2010.

PATTON, M. Q. Qualitative research and evaluation methods (3 ed.). London: Sage Publications, 2002. is PRENSKY, M. From Digital Natives to Digital Wisdom. Thousand Oaks, CA: Corwin, 2012.

RIVOLTELLA, P. C. Media Education: modelli, esperienze, profilo disciplinare. Roma: Carocci, 2002.

SELWYN, N. Education and technology: key issues and debates. (2. ed.). London: Bloomsbury, 2017.

SHOLLE, D. The theory of critical pedagogy. Journal of Communication Inquiry, v. 8, n. 2, p. 8-29, 1994.

SIBÍLIA, P. Redes ou paredes: a escola em tempos de dispersão. Tradução de Vera Ribeiro. Rio de Janeiro: Contraponto, 2012.

SILVA, T. T. Documentos de identidade: uma introdução às Teorias de Currículo. $3^{\circ}$ Edição. Belo Horizonte: Editora Autêntica, 2010.

THOMAS, A.; STRATTON, G. What we are really doing with ICT in physical education: a national audit of equipment, use, teacher attitudes, support, and training. British Journal of Educational Technology, v. 37, n. 1, p, 617-632, 2006.

UNESCO. Media and Information Literacy: curriculum for teachers. Paris: Unesco, 2011.

\section{Correspondência}

Allyson Carvalho de Araújo: Doutor em Comunicação pela Universidade Federal de Pernambuco, mestre em Educação e licenciado em Educação Física pela Universidade Federal do Rio Grande do Norte. Professor Associado do Departamento de Educação Física e dos Programas de Pós-graduação em Educação (PPGEd) e Educação Física (PPGEF) da Universidade Federal do Rio Grande do Norte.

E-mail: allyssoncarvalho@hotmail.com

Jeane Felix da Silva: Doutora em Educação pela Universidade Federal do Rio Grande do Sul, mestre em Educação e licenciada em Pedagogia pela Universidade Federal da Paraíba. Professora do Setor de Didática, Centro de Educação, Universidade Federal de Alagoas e do Programa de Pós-graduação em Educação (PPGEd) da Universidade Federal da Paraíba.

E-mail: jeanefelix@gmail.com 
Alan Patrick Ovens: Doutor pela University of Queensland. Professor na School of Curriculum and Pedagogy da Faculty of Education and Social Work da University of Auckland, Nova Zelândia. Diretor do Richard Tinning Research Unit.

E-mail: a.ovens@auckland.ac.nz

Jorge Dorfman Knijnik: Doutor em Psicologia Social pela Universidade de São Paulo, mestre e graduado em Educação Física pela mesma instituição. Professor do Centre for Education Research e do Institute for Culture \& Society na Western Sydney Universit, Austrália.

E-mail: j.knijnik@westernsydney.edu.au

Texto publicado em Currículo sem Fronteiras com autorização dos autores. 